\title{
The Role of Adrenergic Agonists on Glycogenolysis in Rat Hepatocyte Cultures and Possible Involvement of NO
}

\author{
J. HODIS, N. KUTINOVÁ-CANOVÁ, P. POTMĚŠIL ${ }^{1}$, L. KAMENÍKOVÁ, \\ E. KMONÍČKOVÁ ${ }^{1}$, Z. ZÍDEK ${ }^{1}$, H. FARGHALI \\ Institute of Pharmacology, First Faculty of Medicine, Charles University and ${ }^{1}$ Institute of \\ Experimental Medicine, Academy of Sciences of the Czech Republic, Prague, Czech Republic
}

Received May 12, 2006

Accepted July 24, 2006

On-line available August 22, 2006

\begin{abstract}
Summary
Certain liver metabolic diseases point to the presence of disturbances in glycogen deposition. Epinephrine raises the cAMP level that activates protein kinase A leading to the activation of phosphorylase and glycogen breakdown. In the present report, we sought to investigate whether NO is produced during adrenoceptor agonist-induced glycogenolysis in rat hepatocytes in cultures. Isolated glycogen rich rat hepatocytes in cultures were used. NO production $\left(\mathrm{NO}_{2}{ }^{-}\right)$was assessed under the effect of adrenergic agonists and adrenergic agonist/antagonist pairs, dibutyryl cyclic AMP sodiumpotassium salt (db-cAMP), NO synthase (NOS) inhibitors $\mathrm{N}^{\omega}$-nitro-L-arginine methyl ester (L-NAME), aminoguanidine (AG) and the NO donor S-nitroso-N-acetyl penicillamine (SNAP). The inducible NO synthase (iNOS) mRNA was examined by the reverse transcription-polymerase chain reaction (RT-PCR). Glycogenolysis was quantified by glucose levels released into medium. The amount of glucose and $\mathrm{NO}_{2}{ }^{-}$released by hepatocytes was increased as a result of epinephrine, phenylephrine or db-cAMP treatments. The increase in glucose and $\mathrm{NO}_{2}^{-}$released by epinephrine or phenylephrine was blocked or reduced by prazosin pretreatment and by NOS inhibitors aminoguanidine and LNAME. iNOS gene expression was up-regulated by epinephrine. It can be concluded that glycogenolysis occurs through $\alpha$-adrenoceptor stimulation and a signaling cascade may involve NO production.
\end{abstract}

Key words

Glycogen $\bullet$ Glycogenolysis $\bullet$ NO $\bullet$ iNOS $\bullet$ Epinephrine $\bullet$ cAMP

\section{Introduction}

Liver damage which occurs in certain metabolic diseases may point to the presence of disturbances in glycogen deposition due to various reasons that either promote accumulation of glycogen in the liver or lead to depressed levels of liver glycogen where the two processes are reciprocally controlled. Control of hepatic glycogenolysis involves intricate paracrine and endocrine communication between hepatocytes and other cells (Decker 1990, Huber and Keppler 1990, Borgs et al. 1996). Signaling pathways that are included in hormoneinduced glycogen degradation are well documented. Glucagon is known to be the most potent activator of glycogenolysis and its role in glycogenolysis has been extensively studied. In addition, epinephrine raises the 
cAMP level that activates protein kinase A (PKA) and this in turn leads to the activation of phosphorylase and glycogen breakdown. At the same time, PKA phosphorylates and helps to inactivate glycogen synthase. This means that the latter two hormones on the one hand, and insulin on the other, determine which one predominates. This helps to ensure that when glycogen is broken down, it is also not being synthesized; the control mechanisms are reciprocal in the two systems (Elliott and Elliott 2001). The adrenergic regulation of glycogenolysis in hepatocytes is of importance under both physiological and pathological conditions. A number of studies were conducted in this regard where $\alpha_{1}$ and $\beta$ receptors were reported to exist in hepatocytes (Van Ermen and Fraeyman 1994, Shiroyama et al. 1998, Fabbri et al. 1999, Vardanega-Peicher et al. 2000, Manzl et al. 2002). The reported data indicate that several types of adrenergic receptors may play a role in glycogenolysis. Even a change from $\beta$ - to $\alpha$-adrenergic glycogenolysis was reported in the rat liver (Moriyama et al. 1997).

Though the pathways that modulate glycogen levels in the liver are almost clear, the role of nitric oxide (NO) in this process is not extensively studied. Currently it is well known that $\mathrm{NO}$ possesses functional regulatory effects in all organs, tissues and cells which have been hitherto examined, including the liver. The role of NO in a number of liver functions has been investigated in previous studies (Muriel 2000, Chang et al. 2004). It was suggested that nitric oxide synthases (NOSs) are new players in the pathophysiology of some liver diseases (Moreau 2002). Reports indicate that NO affects glycogen and glucose homeostasis (Borgs et al. 1996, Stadler et al. 1995, Horton et al. 1994a,b, Sugita et al. 2002). However, it is still not clear how NO is involved in the modulation of glycogenolytic pathways or in liver glycogen homeostasis. Modulation of the reactions involved in the production and release of glucose from hepatocytes is a possible approach to developing new classes of oral hypoglycemic agents (Proietto and Andrikopoulos 2004). In the present work, we investigated whether $\mathrm{NO}$ is produced during adrenoreceptor agonist-induced glucose release by rat hepatocytes in cultures. To achieve this goal, isolated glycogen-rich rat hepatocytes in culture were used for the glycogenolysis studies and NO expression was assessed under the effect of various adrenergic agonists, adrenergic agonist/antagonist pairs, cAMP and nitric oxide donors.

\section{Methods}

\section{Chemicals and reagents}

William's medium E, supplemented with gentamicin, L-glutamine and $10 \% \mathrm{FBS}$, bovine serum albumin fraction $\mathrm{V}$ (BSA), epinephrine, phenylephrine, prazosin, propranolol (+/- 1-isopropylamino-3-(1naphthyloxy)-2-propranolon hydrochloride), sulfanilic acid, N-(1-Naphtyl)ethylendiamine dihydrochloride, dibutyryl cyclic AMP sodium-potassium salt (db-cAMP), $\mathrm{N}^{\omega}{ }^{\omega}$-nitro-L-arginine methyl ester (L-NAME), aminoguanidine (AG), S-nitroso-N-acetyl penicillamine (SNAP), dimethyl sulfoxide (DMSO) were obtained from Sigma-Aldrich (Prague). Collagenase and Glucose assay kit were obtained from Sevapharma (Prague). All other chemicals were obtained from standard sources and were the highest grade available.

Animals, isolation and preparation of glycogen-rich hepatocyte cultures

Male rats of Wistar strain (Velaz, Lysolaje, 200250 g body weight) were used throughout the present studies. Hepatocytes were isolated from rats by the standard two-phase perfusion method where collagenase was included in the second phase as previously reported (Farghali et al. 1994).

After isolation, cell viability as assessed by trypan blue was more than $90 \%$. The preparation of glycogen-rich hepatocytes was carried out according to Shiroyama et al. (1998) with modification. Briefly, $1.5 \times 10^{6}$ hepatocytes from untreated animals were plated into 35-mm collagen-coated cell culture dishes and maintained at $37{ }^{\circ} \mathrm{C}, 95 \%$ air, and $5 \% \mathrm{CO}_{2}$ in William's medium E, supplemented with gentamicin, L-glutamine $10 \mathrm{mM}$ HEPES, $6 \%$ fetal bovine serum, $10^{-7} \mathrm{M}$ insulin and $20 \mathrm{mM}$ glucose. The glycogen-rich cells were used to determine glycogenolytic glucose release. High glycogen content of hepatocytes was confirmed by both biochemical and histochemical means (Shiroyama et al. 1998). This model proved to be convenient for the study of glycogenolysis.

\section{Measurement of glucose release}

The medium of the glycogen-rich hepatocytes was changed to Dulbecco's phosphate buffered saline (containing neither glucose nor amino acids, nor lactate) just before the appropriate treatment. Control hepatocyte cultures without agonist addition were always included to express the precise glycogenolytic effect of agonists. 
Epinephrine $\left(10^{-7}-10^{-4} \mathrm{M}\right)$, phenylephrine $\left(10^{-7}-10^{-4}\right.$ $\mathrm{M})$, isoprenaline $(2 \mu \mathrm{M})$, dobutamine $(10 \mu \mathrm{M})$ without or preceded with prazosin or propranolol to the glucose-free Dulbecco's phosphate buffered saline medium. The time course of glycogenolysis was followed till $120 \mathrm{~min}$ of incubation. Glycogenolysis was followed up by estimation of medium glucose medium levels spectrophotometrically according to an enzymatic glucose assay kit.

Nitric oxide production and other biochemical measurements

The time course of NO production, cell protein content (protein kit Sigma-Aldrich, Czech Republic), ALT leakage (Biocon, Germany) from cells into the medium were measured at appropriate time intervals as indicated in the section Results. NO production was determined by measuring the levels of its oxidation products $\mathrm{NO}_{2}{ }^{-}$and $\mathrm{NO}_{3}{ }^{-}$in the culture medium. This was detected colormetrically $(540 \mathrm{~nm})$ by Griess reagent. The nitrite levels were extrapolated from $\mathrm{NaNO}_{2}$ calibration curve.

\section{iNOS expression in cultured hepatocytes by RT-PCR}

The 24-h cultured hepatocytes were used for the reverse transcriptase-polymerase chain reaction (RTPCR). Total RNA from hepatocytes was isolated by the standard procedure described earlier (Farghali et al. 2002) for iNOS. The relative level of iNOS mRNA expression was determined after normalization to the $\beta$-actin signal to account for variability in the amount of RNA that had been extracted from the cells.

\section{Statistical analysis}

All experiments were performed at a minimum 6-8 times in triplicates (means of at least of 18-24 values, see results) with blind samples as the media background. The statistical significance of the difference of mean scores was determined using the unpaired Student's $t$-test. Results showing $\mathrm{p}<0.05$ were considered statistically significant.

\section{Results}

The amount of glucose and nitrite released by glycogen-rich hepatocytes was significantly increased as a function of time by adrenergic drug treatment. Figure 1 demonstrates that at sampling times 30 and $60 \mathrm{~min}$, both glucose and nitrite levels were higher under adrenergic
Table 1. The relative effect of incubation (30 and $60 \mathrm{~min}$ ) with 5 treatments on nitrite production and glycogenolysis in hepatocyte culture after $24 \mathrm{~h}$ expressed in \% of control (mean values of 20-24 cultures \pm S.E.M.)

\begin{tabular}{lcccc}
\hline \multirow{2}{*}{ Treatments } & \multicolumn{4}{c}{ Percent of control \pm S.E.M.** } \\
\cline { 2 - 5 } & \multicolumn{2}{c}{ Nitrite after } & \multicolumn{2}{c}{ Glucose after } \\
& $\mathbf{3 0}$ min & $\mathbf{6 0}$ min & $\mathbf{3 0 ~ m i n}$ & $\mathbf{6 0}$ min \\
\hline \multirow{2}{*}{$A G$} & $78 \pm 7^{*}$ & $38 \pm 8^{*}$ & $91 \pm 15$ & $90 \pm 13$ \\
$A G+E p i$ & $83 \pm 3^{*}$ & $79 \pm 6^{*}$ & $103 \pm 15$ & $158 \pm 13^{*}$ \\
$N A M E$ & $90 \pm 10$ & $78 \pm 9^{*}$ & $100 \pm 3$ & $140 \pm 3^{*}$ \\
$N A M E+E p i$ & $158 \pm 7^{*}$ & $78 \pm 6$ & $126 \pm 13$ & $93 \pm 15$ \\
$d b-c A M P$ & $120 \pm 10^{*}$ & $160 \pm 8^{*}$ & $140 \pm 10^{*}$ & $90 \pm 25$ \\
\hline
\end{tabular}

AG - aminoguanidine, Epi - epinephrine, NAME - $\mathrm{N}^{\omega}$-nitro-Lagrinine methyl ester, db-cAMP - dibutyryl cyclic AMP sodiumpotassium salt. * significant difference from control $(P<0.05)$. ** amount of produced nitrite or glucose in treated cultures in percent of the control culture

drugs treatment as compared to the control treatment. Nitrite level was also higher in both cases as compared to control, the difference being significant $60 \mathrm{~min}$ after incubation of hepatocytes in culture. The increase in the amount of glucose and nitrite induced by epinephrine or phenylephrine was completely blocked or significantly reduced by prazosin pretreatment (Fig. 2). This figure also demonstrates that the pretreatment with propranolol has no effect on epinephrine-induced increase in glucose or nitrite production. In hepatocyte cultures, treatment with epinephrine increased iNOS gene expression as measured by RT-PCR. Figure 3 shows a representative photograph of an agarose gel of iNOS mRNA levels. In non-induced, control hepatocytes, iNOS mRNA was detected. Following treatment with epinephrine there was a marked PCR production of iNOS that was observed after $60 \mathrm{~min}$ exposure of hepatocyte in culture. At the posttranslational level, Table 1 shows the relative effect of incubation (30 and $60 \mathrm{~min}$ ) with five treatments on nitrite production and glycogenolysis in hepatocyte cultures after $24 \mathrm{~h}$. Both aminoguanidine at high concentrations $(10 \mathrm{mM})$ and L-NAME $(10 \mathrm{mM})$ were able to significantly decrease NO production and glycogenolysis induced by epinephrine. This effect was measurable and significant in most cases at 30 and $60 \mathrm{~min}$, the aminoguanidine effect being more potent.

\section{Discussion}

The liver plays a central role in the control of 
Fig $1 \mathrm{~A}$

¿Epinephrine : Phenylephrine

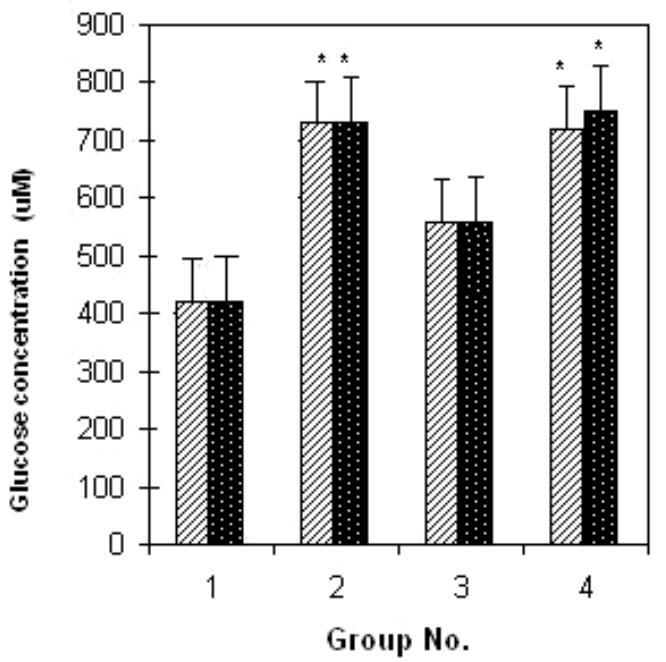

Fig 1B Epinephrine : Phenylephrine

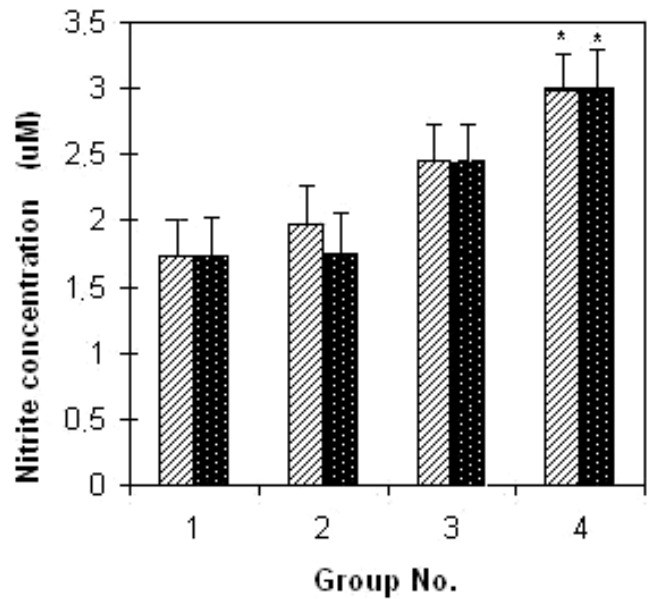

Fig. 1 (A, B). Glucose (A) and nitrite (B) levels under epinephrine and phenylephrine treatments. 1) 30 min incubation control, 2) $30 \mathrm{~min}$ incubation epinephrine and phenylephrine, 3) 60 min incubation control, 4) 60 min incubation epinephrine and phenylephrine. * Significantly different from control $(\mathrm{P}<0.05)$.

Fig 2A

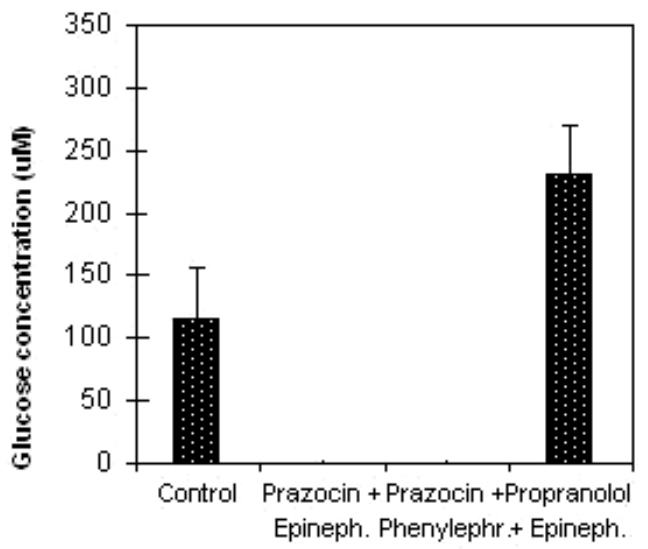

Fig 2B

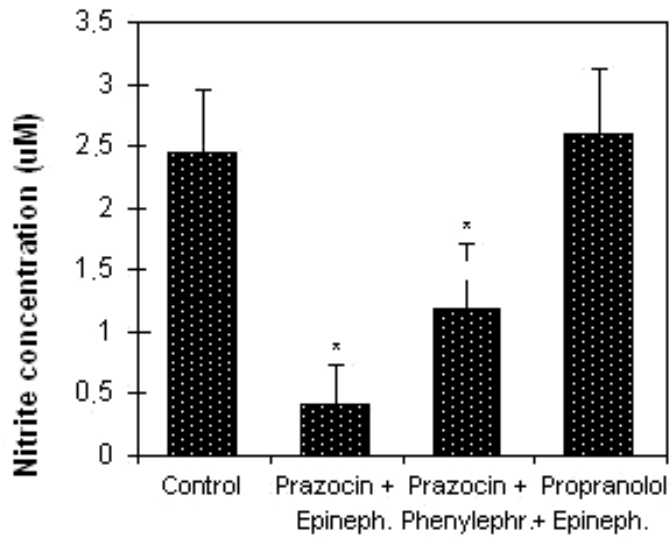

Fig. 2. (A, B). The effect of prazosin and propranolol pretreatment on glucose (A) and nitrite (B) increase induced by epinephrine and phenylephrine treatments. $*$ Significantly different from control $(P<0.05)$.

glucose production. Due to the importance of hepatocytes in this regard, intensive research is directed towards finding out pharmacological means that modulate hepatocyte signaling pathways leading to glycogenolysis or modulation of gluconeogenesis. This important aspect may be directed to patients with type 2 diabetes who are going on to require insulin therapy to achieve glucose control. New classes of oral hypoglycemic agents could be targeting the inappropriately elevated endogenous glucose production. Among several approaches reported (Moriyama et al. 1997) there are modulators of glycogenolysis and gluconeogenesis, inhibitors of stimulatory hormones or their receptors. The present data demonstrate that epinephrine and phenylephrine, but not isoprenaline or dobutamine, enhanced glucose release in hepatocytes in culture. However, reports indicate that various adrenergic, both alpha and beta agonists, stimulate glycogenolysis depending on animal age and zones of hepatocytes (Fraeyman and Van Ermen 1993, Sanghani and Scarpace 1994, Tosh and Agius 1994).

Nevertheless, the present study demonstrates that NO is released, probably as a common denominator 


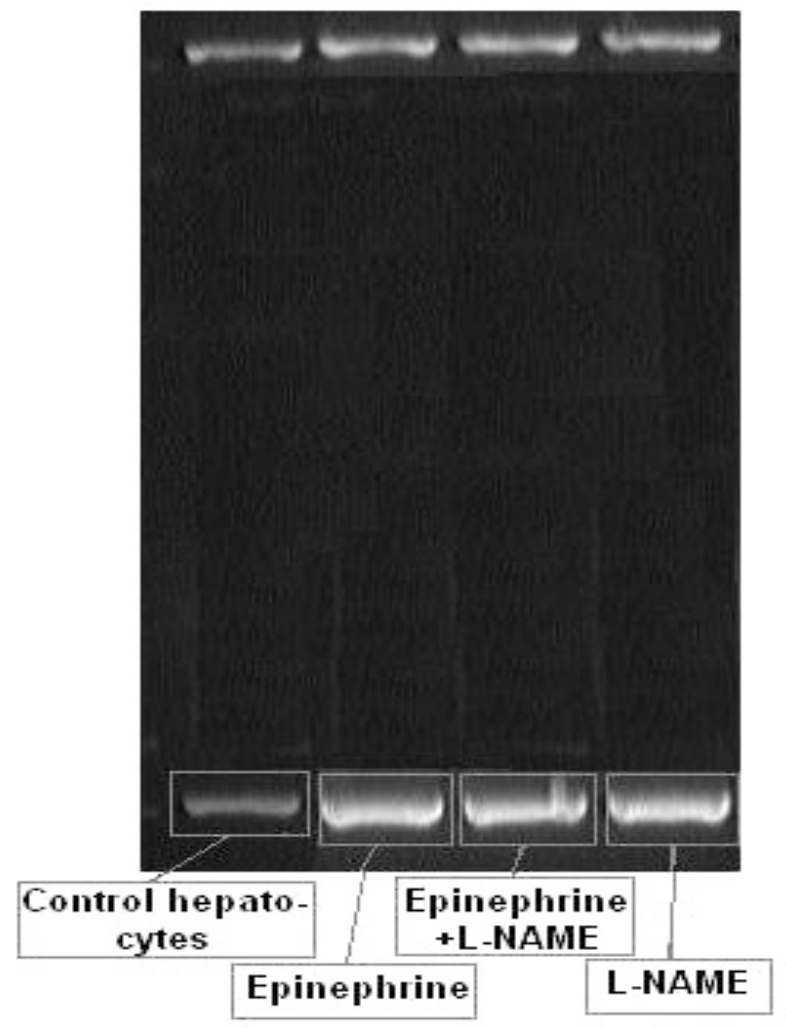

Fig. 3. A representative photograph of an agarose gel of iNOS mRNA levels.

signal during the process of glycogenolysis as revealed for both an adrenergic-agonistic effect with consequent glucose release. Measurement of glycogenolysis was carried out by the preparation of glycogen-rich hepatocytes according to Shiroyama et al. (1998) which were used to determine glycogenolytic glucose release in a glucose-free incubation medium. The incubation of hepatocytes in William's medium E containing high glucose and insulin concentrations (to obtain glycogenrich hepatocytes) and the switching into Dulbecco's phosphate buffered saline medium should turn down to a minimum the expected pathway of gluconeogenesis which is based mainly on lactate as a reactant (Meyer et al. 2003). Dulbecco's phosphate buffered saline medium as the only medium in the second part of the experiment disrupts additional pathways of forming glucose based on the uptake of reaction substrates from extra-cellular environment.

The role of nitric oxide (NO) in a number of liver functions has been investigated in several previous studies. It was suggested that nitric oxide synthases (NOSs) are involved in the pathophysiology of some hepatic diseases (Moreau 2002). In several other reports it was found that NO affects glycogen and glucose homeostasis (Borgs et al. 1996, Stadler et al. 1995, Horton et al. 1994a,b, Sugita et al. 2002). However, it is still not clear how NO is involved in the modulation of glycogenolytic pathways under physiological conditions.

Interestingly enough, it was found in the present report that the $\alpha_{1}$-selective adrenoceptor blocker (prazosin) inhibited epinephrine-induced glycogenolysis and also NO production.

The present data provide evidence that $\alpha$-adrenergic-induced glycogenolysis is realized via the agonist/adenylyl cyclase/protein kinase A (PKA) cascade and cAMP signaling pathway, involving downstream NO production. This is supported by the fact that the stable congener to cAMP, db-cAMP, produced identical effects on glycogenolysis and NO production as epinephrine. Moreover, SNAP used at the concentrations of 25$250 \mu \mathrm{M}$ in hepatocyte cultures led to a dose-dependent increase in basal glycogenolysis (data not shown). Hence, our study suggested that endogenous NO produced downstream of agonist/receptor signal transduction pathway and coupling through an isoform of NOS plays a role in glycogenolysis. This is further supported by our data demonstrating that both L-NAME and aminoguanidine were able to partially inhibit the glycogenolytic effect of epinephrine. Moreover, iNOS mRNA was significantly enhanced by epinephrine. Indeed, the role of iNOS in adrenoceptor-stimulated glycogenolysis under physiological conditions was not yet reported according to the available data. The present data do not rule out the involvement of either NOS isoform in contributing to the glycogenolytic signaling pathway(s) in isolated cultured hepatocytes. Maintaining blood glucose levels within a physiological range is an important function requiring multiple metabolic pathways and involving several cell types, including the important role for hepatocytes. The importance of this study, therefore, stems out from the fact that hepatocytes are critical for glucose homeostasis (Klover and Mooney 2004). Hepatocytes can respond to either feeding or fasting by storing or producing glucose as necessary. Glucagon, catecholamines and insulin are well-studied regulators of glycogen stores. Transcriptional regulation of rate-limiting enzymes and modulation of enzyme activity through phosphorylation and allosteric regulation are involved. Therefore, the contribution of more signals which are involved in these functions would be significant. Our data indicate that under the present experimental conditions, glycogenolysis occurs through $\alpha$-adrenoreceptor stimulation, which is known to be 
realized via the adenylyl cyclase/cAMP protein kinase A signaling cascade, may involve NO production downstream of receptor-cAMP pathways. It was reported that iNOS is regulated mainly at the transcriptional level by several transcriptional factors such as nuclear transcription factor- $\kappa \mathrm{B}(\mathrm{NF}-\kappa \mathrm{B})$, Fos/Jun, CCAAT/ enhancer binding protein $(\mathrm{C} / \mathrm{EBP})$, interferon- $\gamma(\mathrm{IFN}-\gamma)$ activation site (GAS), and IFN regulatory factor (IRF) and some of these transcription factors (AP-1, NF- $\kappa \mathrm{B}$, and $\mathrm{C} / \mathrm{EBP}$ ) are reported to be regulated by glycemia. Therefore, there is a possibility that glycogenolysis may be involved in the regulation of iNOS gene expression via the regulation of these transcriptional factors (Won et al. 2003).

This gives further proof about the diversity of the roles of NO (whether at physiological levels or the induced ones) in hepatocyte metabolic functions.

\section{Acknowledgements}

The author would like to thank Libuše Šlehobrová, Alena Hloušková and Mgr. Jana Kř́žzová for their skilful technical assistance. This study was supported by grant IGA MZ NL/7418-3.

\section{References}

BORGS M, BOLLEN M, KEPPENS S, YAP SH, STALMANS W, VANSTAPEL F: Modulation of basal hepatic glycogenolysis by nitric oxide. Hepatology 23: 1564-1571, 1996.

CHANG K, LEE SJ, CHEONG I, BILLIAR TR, CHUNG HT, HAN JA, KWON YG, HA KS, KIM YM: Nitric oxide suppresses inducible nitric oxide synthase expression by inhibiting post-translational modification of 1 kappa B. Exp Mol Med 36: 311-324, 2004.

DECKER K: Biologically-active products of stimulated liver macrophages (Kupffer cells). Eur J Biochem 192: 245 261, 1990.

ELLIOTT WH, ELLIOTT DC: Biochemistry and Molecular Biology, Oxford University Press, 2001, pp 222-233.

FABBRI E, BUZZI M, BIONDI C, CAPUZZO A: Alpha-adrenoceptor mediated glucose release from perifused catfish hepatocytes. Life Sci 65: 27-35, 1999.

FARGHALI H, KAMENÍKOVÁ L, HYNIE S: Preparation of functionally active immobilized and perfused mammalian cells: an example of hepatocyte bioreactor. Physiol Res 43: 121-125, 1994.

FARGHALI H, CANOVÁ N, GAIER N, LINCOVÁ D, KMONÍČKOVÁ E, STŘEŠTÍKOVÁ P, MAŠEK K: Inhibition of endotoxemia-induced nitric oxide synthase expression by cyclosporin A enhances hepatocyte injury in rats: amelioration by NO donors. Int Immunopharmacol 2: 117-127, 2002.

FRAEYMAN N, VAN ERMEN A: Influence of aging on the beta-receptor and glucagon-receptor-mediated glycogenolysis in rat hepatocytes. Mech Ageing Dev 70: 115-126, 1993.

HORTON RA, KNOWLES RG, TITHERADGE MA: Endotoxin causes reciprocal changes in hepatic nitric-oxide synthesis, gluconeogenesis, and flux through phosphoenolpyruvate carboxykinase. Biochem Biophys Res Commun 204: 659-665, 1994a.

HORTON RA, CEPPI ED, KNOWLES RG, TITHERADGE MA: Inhibition of hepatic-gluconeogenesis by nitric oxide: a comparison with endotoxic-shock. Biochem J 299: 735-739, 1994b.

HUBER M, KEPPLER D: Eicosanoids and the liver. Prog Liver Dis 9: 117-141, 1990.

KLOVER PJ, MOONEY RA: Hepatocytes: critical for glucose homeostasis. Int J Biochem Cell Biol 36: 753-758, 2004.

MANZL C, SCHUBERT M, SCHWARZBAUM PJ, KRUMSCHNABEL G: Effects of chemical anoxia on adrenergic responses of goldfish hepatocytes and the contribution of alpha- and beta-adrenoceptors. J Exp Zool 292: 468476, 2002.

MEYER C, STUMVOLL M, WELLE S, WOERLE HJ, HAYMOND M, GERICH J: Relative importance of liver, kidney, and substrates in epinephrine-induced increased gluconeogenesis in humans. Am J 285: 819-826, 2003.

MOREAU R: Are nitric oxide synthases new players in the pathopysiology of fulminant hepatic failure? J Hepatol 37 : 678-680, 2002.

MORIYAMA M, NAKANISHI Y, TSUYAMA S, KANNAN Y, OHTA M, SUGANO T: Change from beta- to alphaadrenergic glycogenolysis induced by corticosteroids in female rat liver. Am J Physiol 273: R153-R160, 1997.

MURIEL P: Regulation of nitric oxide synthesis in the liver J Appl Toxicol 20: 189-195, 2000. 
PROIETTO J, ANDRIKOPOULOS S: Molecular mechanisms of increased glucose production: identifying potential therapeutic targets $J$ Investig Med 52: 389-393, 2004.

SANGHANI MP, SCARPACE PJ: Atypical beta-adrenergic receptors in rat liver: evidence for transient expression during aging. J Gerontol 49: B60-B64, 1994.

SHIROYAMA K, MORIWAKI K, YUGE O: The direct effect of dopamine on glucose release from primary cultured rat hepatocytes. In vivo 12: 527-529, 1998.

STADLER J, BARTON D, BEIL-MOELLER H, DIEKMANN S, HIERHOLZER C, ERHARD W, HEIDECKE CD: Hepatocyte nitric oxide biosynthesis inhibits glucose output and competes with urea synthesis for L- arginine. Am J Physiol 268: G183-G188, 1995.

SUGITA H, KANEKI M, TOKUNAGA E, SUGITA M, KOIKE C, YASUHARA S, TOMPKINS RG, JEEVENDRA M: Inducible nitric oxide synthase plays a role in LPS-induced hyperglycemia and insulin resistance. Am J Physiol Endocrinol Metab 282: E386-E394, 2002.

TOSH D, AGIUS L: Glycogen degradation by adrenergic agonists and glucagon in periportal and perivenous rat hepatocyte cultures. Biochim Biophys Acta 1221: 238-242, 1994.

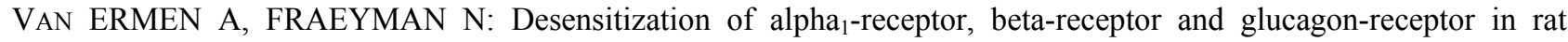
hepatocytes -influence of ageing. Mech Ageing Dev 75: 45-58, 1994.

VARDANEGA-PEICHER M, LOPES G, LIMA FB, CURI R, NAKANO LC, BAZOTTE PB: Time sequence of changes in the responsiveness of glycogen breakdown to adrenergic agonists in perfused liver of rats with insulin-induced hypoglycemia. Braz J Med Biol Res. 33: 805-813, 2000.

WON JS, IM YB, KEY L, SINGH I, SINGH AK: The involvement of glucose metabolism in the regulation of inducible nitric oxide synthase gene expression in glial cells: possible role of glucose-6-phosphate dehydrogenase and CCAAT/enhancing binding protein. J Neurosci 23: 7470 -7478, 2003.

\section{Corresponding author}

J. Hodis, Institute of Pharmacology; First Faculty of Medicine, Charles University, Albertov 4, 12000 Prague 2, Czech Republic. E-mail: hodik@volny.cz 